\title{
INVESTASI ASING DI KALIMANTAN TIMUR \\ DALAM KERJASAMA BILATERAL: \\ TINJAUAN MELALUI PERSPEKTIF RATIONAL CHOICE
}

Rahmah Daniah ${ }^{1}$

\begin{abstract}
Natural resources (SDA) potential in East Kalimantan (Kal-Tim) has a significant value, such as high income-tax local, until investors attended, specifically South Korea and Rusia. This article elaborates the concept of "Rational Choice", which is analysis about cost, benefit, risk and how to minimize risk host country in alternative decisions. Therefore, as argued in this article, investors had positive and negative impacts to local development.
\end{abstract}

Keywords : East Kalimantan, Impact, Investor, Rational Choice

\section{Pendahuluan}

Geografis di Kalimantan Timur (KalTim) cukup menguntungkan dilihat dari konteks luas wilayah 20.865.774 ha, dengan kalkulasi daratan 19.844.117 ha dan luas pengelolaan laut 1.021 .657 ha atau lebih $12 \%$ dari luas wilayah nasional dan $45.77 \%$ dari luas Pulau Kalimantan, dengan kapasitas luas wilayah yang besar maka pengelolaan akan sumber daya sebagai pemasukan daerah cukup signifikan pada provinsi ini.

Hal ini berdampak pada latar belakang munculnya optimisme dalam pembangunan di Kalimantan Timur karena peningkatan yang cukup signifikan dalam masalah ekspor sumber daya alam di Kal-Tim, terlihat dari ekspor Kal-Tim antara lain berupa komoditi batubara, kayu olahan, kimia, CPO, perikanan, manufaktur dan lainnya, pada tahun 2011 perolehan Pendapatan Asli Daerah (PAD) sebesar Rp. 3.405 Triliun.(Kal-Timprov.go.id)

Dalam perkembangannya ekspor non migas dan migas tahun 2011 mencapai US\$. 9 Milyar. Berdasarkan data dari Yadi Sabiyannor sebagai Kepala Badan Pelayanan dan Penanaman Modal Daerah (BPPMD), nilai minat investasi Penanaman Modal Asing (PMA) di Kal-Tim pada Februari 2012 berpengaruh positif sehingga mencapai angka Rp. 63,37 Triliun. Provinsi Kal-Tim menjadi sebagai salah satu Koridor Ekonomi Nasional (National Economic Coridor), bersama Provinsi Riau dan Sumatera Utara berdasarkan Inpres Nomor. 01 tahun 2010 dengan basis Klaster Industri berbasis Pertanian Oleochemical di Kawasan Maloy Kutai Timur, kota Bontang sebagai Klaster Industri berbasis minyak dan gas bumi (migas), serta kota

\footnotetext{
${ }^{1}$ Staf pengajar di prodi Hubungan Internasional, Universitas Mulawarman, Kalimantan Timur.
} 
Balikpapan sebagai Kawasan Industri Kariangau melalui pelabuhan Peti kemas Karingau yang diperkirakan selesai Juni 2012, ketiganya menjadi Kawasan Ekonomi Khusus (KEK).(Kal-Timprov.go.id)

\section{Keberadaan Investasi Asing di Kalimantan Timur}

Sebagai salah satu aktor yang mampu memberikan pengaruh positif bagi perkembangan pembangunan daerah yang memiliki basis SDA besar, maka kehadiran PMA di suatu negara menjadi penting, ketika kehadiran mereka mampu menghadirkan kekuatan modal, teknologi dan sistem manajemen yang baik dalam mengelola dan eksploitasi potensi SDA, suatu daerah tertentu dalam kerangka kerjasama bilateral antar negara.

Adanya UU No.1/1967 tentang Penanaman Modal Asing (PMA) dan UU No.6/1968 tentang Penanaman Modal Dalam Negeri (PMDN), yang kemudian direvisi melalui UU No.11/1970 PMA dan UU No.12/1970 PMDN. Secara nasional, dijadikan dasar dalam terbukanya pintu investasi pembangunan masing-masing daerah. Keberadaan UU ini sebagai bentuk perlindungan hukum bagi masuknya para investor asing. Kehadiran PMA di Indonesia bagian dari bentuk pemerintah sebagai upaya menjalankan usaha dengan tidak menggunakan sumber cadangan devisa Indonesia dalam segala bentuk operasionalisasinya.

UU PMA juga dikembangkan keberadaannya di Kal-tim, sebagai salah satu provinsi yang memiliki peluang investasi asing yang besar, terlihat dari tingginya potensi SDA Kal-Tim yang ada. Hal ini kemudian tertuang dalam statement dari Gubernur Kal-Tim, DR. H. Awang Faroek Ishak, M.Si, yaitu berupa "Peluang investasi di Kalimantan Timur sangat terbuka luas hampir di segala sektor pembangunan pasca ditetapkan Koridor Ekonomi Nasional", dalam acara International Fair Trade di Jakarta.(bppmd.go.id)

Masuknya PMA di Kal-Tim bagian dari upaya realisasi dalam Masterplan Percepatan dan Perluasan Pembangunan Ekonomi Indonesia (MP3EI) yang dicanangkan oleh pemerintah Pusat. Hasilnya MP3EI kemudian diterjemahkan dalam keberadaan PMA sebagai salah satu faktor pendukung masterplan tersebut.

Dukungan dari Pemprov Kal-Tim ini kemudian dimanisfestasikan dalam bentuk keikutsertaan infrastruktur internasional (Indonesian International Infrastructur Conference and Exhibition/IIICE) di Jakarta Convention Center (JCC) pada 12-14 April 2011. Hasilnya para investor asing yang terlibat banyak sekali yang ingin melakukan kerjasama, diantaranya Jepang, Perancis, Korea Selatan dan Jerman

Diantaranya pada tahun 2010, Indonesia-Korea Selatan kemudian menandatangani MoU 12 Kesepakatan dalam kerangka kerjasama bilateral bidang pembangunan infrastruktur di Seoul melalui Presiden RI, Susilo Bambang Yudoyono dan Perdana Menteri Republik Korea, Han Duck- 
Soo. Salah satu dari 12 kesepakatan tersebut, diantaranya adalah kerjasama PT. Nuansa Cipta Coal Investment dengan Kenertec Co, Posco Engineer \& Construction Co, Ltd dan Samsung Securities, merupakan kerjasama dibidang energi dan sumberdaya mineral untuk pembangunan operasi pabrik pencairan batubara dengan nilai investasi US $\$ 5,5$ juta di Kalimantan Timur.

Penandatanganan MoU selanjutnya, pada pembangunan jaringan rel kereta api antara Pemprov Kal-Tim dan Kalimantan Rail PTE Ltd (investor dari Rusia) di Hotel Indonesia. Jakarta, yang dimulai pada tahun 2013. Mou ini berisi tentang Pembangunan rel kereta api Kubar-Balikpapan oleh Kalimantan Rail PTE Ltd senilai Rp16 triliun, perluasan kilang minyak di Desa Api-Api Kecamatan Penajam, Kabupaten Penajam Paser Utara (PPU) senilai Rp. 4 triliun dan pembukaan pencetakan sawah senilai Rp. 9 triliun. Sehingga target pemerintah pada akhirnya mencapai nilai investasi sebesar Rp. 30 Triliun.(Kal-Tim.go.id)

\section{Rational Choice Kerjasama Bilateral}

Menurut Risse, "Rational choice is instrumental: it is guided by the outcome of action. Action are valued and chosen not for themselves, but as more or less efficient means to a further end".(Risse, 2000, p.3)

Rasionalitas terjadi apabila seorang pembuat keputusan akan mengambil pilihan terbaik dari sekian banyak alternatif yang tersedia. Setiap pilihan tersebut memiliki dampak bagi kehidupan sosial masyarakat. Sehingga essensi setiap pengambilan kebijakan adalah memilih dari sekian banyak alternatif yang memiliki kesinambungan bagi kehidupan suatu bangsa. (Aranson, 1996, p.1)

Rational choice atau pilihan rasional, terjadi apabila seorang pembuat keputusan mampu mengambil pilihan-pilihan alternatif terbaik untuk mencapai kepentingan dengan tujuan jangka panjang.

Dalam menjelaskan pilihan rasional secara rigit, menggunakan sumber kalkulasi cost dan benefit atau sering kali disebut dengan istilah "untung-rugi" dalam setiap pengambilan kebijakan. Tetapi pilihan rasional ini mengutamakan tujuan pada keuntungan jangka panjang, dan perolehan keuntungannya dalam waktu yang lama.

\section{Cost Host Country}

Melihat fenomena dalam kerjasama bilateral kedua negara, merupakan bagian yang terintegrasi dalam komitmen mengembangkan perluasan jaringan hubungan kerjasama ekonomi yang mencakup segala bidang pembangunan kedua negara. Sehingga dalam sebuah mekanisme hubungan bilateral posisi kedua negara tersebut seimbang dalam memperoleh keuntungan.

Investasi adalah salah satu faktor dalam rangka percepatan pembangunan bagi negara berkembang, khususnya Kal-Tim yang berusaha menarik modal asing seperti private capital untuk mendanai sektor strategis pembangunannya, terutama pada sektor 
industri.

Realisasi pada Pendapatan Asli Daerah (PAD) di Kal-Tim pada urutan ketiga setelah Jakarta dan Jawa Timur, angka yang cukup baik dilihat dari kondisi sumberdaya alamnya. Evaluasi PAD Kal-Tim per tanggal 13 Desember 2011, mencapai angka Rp. 3, 405 Triliun melebihi target sebelumnya di angka Rp. 3, 257 Triliun saja. PAD Kal-Tim dihasilkan melalui pajak daerah, retribusi, pendapatan perusda dan pendapatan yang sah lainnya. Dengan cost ini Kal-Tim cukup memenuhi kebutuhan masyarakat Kal-Tim yang berjumlah 3.777.885 jiwa dengan tingkat kepadatan hanya $19.02 \mathrm{jiwa} / \mathrm{km}^{2}$ (BPPS. 2011). Tetapi dengan luas wilayah Kal-Tim pada angka 20.865.774 ha, maka cost PAD Kal -Tim bergerak lamban dalam pemenuhan pembangunan infrastruktur dengan luas wilayah yang cukup besar.

Maka dasar pada cost ini, memicu KalTim untuk membuka investor luar negeri dalam usaha percepatan pembangunan infrastruktur, agar pos-pos PAD Kal-Tim lebih membesar lagi. Usaha percepatan pembangunan daerah Kal-Tim ini kemudian membuka pintu cost investasi asing senilai $\mathrm{Rp}$. 63, 37 Triliun, dalam rangka sumber dana ini akan dimaksimalkan pada usaha perbaikan infrastruktur industri yang sedang berjalan. Seperti yang terlihat adanya dana investasi yang kemudian membantu pada pembangunan Kal-Tim, seperti rel kereta api (bidang transportasi) dan teknologi pabrik pencairan batubara dengan proses lebih cepat.

\section{Benefit host country}

Upaya realisasi dari sebuah gagasan Masterplan Percepatan dan Perluasan Pembangunan Ekonomi Indonesia, ditindak lanjuti pada keberadaan investasi asing di KalTim sebagai pemicu percepatan pembangunan tersebut. Artinya bantuan investasi Kor-Sel ini bukan saja mendatangkan cost financial tetapi memberi efek keuntungan lain, karena dana APBD Kal-Tim yang tidak digunakan dalam mekanisme ini bisa digunakan pada pengembangan lainnya. Dalam usaha Catching -Up pemerintah daerah inilah kemudian muncul efek keuntungan-keuntungan dibawah ini, seperti :

1. Laju pertumbuhan ekonomi Kal-Tim cukup pesat, terlihat pada tahun 2010 sebesar 4, 95\%. Optimalisasi pada meningkatnya aspek pertanian CPO dan pertambangan yang memberikan nilai pemasukan pajak cukup tinggi. Sehingga berdampak positif pada nilai inflasi dari tahun 2008 sebesar 13,06\% menjadi pada tahun 2010 hanya 7,28\%.

2. Infrastruktur terjadi percepatan akibat bertambahnya devisa, seperti prasarana jalan dan jembatan, seperti pembangunan jalan KM13 Kariangan, jalan tol Balikpapan - Samarinda. Kredit sektor angkutan di Kal-Tim naik sekitar 81,89\% dengan nilai Rp. 3,14 Triliun pada tahun 2011.

3. Pendidikan, seperti pada tahun 2010 Angka Melek Huruf mencapai angka yang 
signifikan sebesar 99,47\% atau buta huruf $0,53 \%$, dan telah mendapatkan penghargaan Anugerah Aksara Utama dari Kementerian Pendidikan Nasional. Kemudian fasilitas pendidikan yang terus ditunjang, bahkan kemudian Kalimantan Timur juga memberikan dana tambahan Biaya Operasional Sekolah (BOS), khususnya pada jenjang pendidikan Sekolah Menengah Atas/MA setiap murid mendapatkan bantuan Rp. 500 ribu per tahun sedangkan Sekolah Kejuruan Rp. 750 ribu per tahun. Alokasi dana yang dianggarkan pada tahun 2010 sebesar Rp. 252,896 Milyar, dengan jumlah murid sebanyak 132.017 siswa yang tersebar di 14 Kabupaten/Kota, penyaluran dari dana BOS diatur melalui Petunjuk Teknis yang disusun oleh masing-masing daerah.

4. Jumlah penduduk miskin di Kal-Tim terus berkurang secara signifikan dari tahun ke tahun. Pada tahun 2008 jumlah penduduk miskin 259.450 orang (8,53 persen), tahun 2009 turun menjadi 245.050 orang $(7,86$ persen), dan tahun 2010 ini berdasarkan data BPS Kalimantan Timur turun menjadi 243.000 orang $(7,66$ persen $)$. Sehingga selama dua tahun ini, terjadi pengurangan jumlah penduduk miskin sebesar 16.450 orang. Hal ini juga diiringi oleh juga pada angka pengangguran, sebesar 11,11 persen pada tahun 2008. Pada Tahun 2009 menurun menjadi 10,83 persen dan tahun 2010 menurun menjadi 10,45 persen namun masih di atas rata-rata nasional sebesar 7,41 persen.

5. Kelistrikan, seperti pembangunan PLTU Gunung Bayan di Kariangau, Pembangunan PLTG Sambera, Pembangunan PLTG Senipah, Pembangunan PLTU Cahaya Fajar KalTim dan pembangunan PLTU Bakrie Power. Pada tahun 2010 daya listrik terpasang di Kalimantan Timur sebesar 621 MW yang digunakan oleh 467.701 rumah tangga, 35.278 usaha dan 245 industri. Kebutuhan total tenaga listrik untuk Kalimantan Timur sampai dengan tahun 2013 adalah 940 MW. (KUAPBD:2012)

\section{Risk Host Country}

Kalkulasi pilihan rasional terletak dari untung-rugi setiap kebijakan yang akan dilaksanakan, sehingga dalam menentukan pilihan-pilihan kebijakan, maka pembuat keputusan melakukan kalkulasi ini dalam rangka memenuhi keuntungan untuk jangka panjang. Setiap kebijakan yang dilakukan oleh pemerintah daerah maka akan muncul keuntungan dan resiko. Hal ini memang sebagai dampak dari setiap pemberlakukan kebijakan tersebut.

Kebijakan membuka investasi asing seluas-luasnya dalam rangka mencari cost sebesar-besarnya yang menimbulkan benefit yang besar, juga memberi dampak negatif lainnya, seperti:

1. Potensi distorsi atau konflik host country, seperti :

a. Masalah angkutan atau transportasi 
akibat adanya ekspansi industri, maka akan terjadi perbaikan infrastruktur jalan yang hanya menghubungkan kawasan industri bisnis saja, seperti jalan penghubung ke Pelabuhan Karingau, pembangunan Jembatan Mahkota II terletak di kota Samarinda, jalan tol penghubung SamarindaBalikpapan, Terpeliharanya Jalan Mantap Nasional, terpeliharanya Jalan Mantap Provinsi. Hal ini menimbulkan ketimpangan infrastruktur atau pola asimetris yang lebih mengarah hanya pada daerah kawasan kota dan industri saja.

b. The defeat of the agricultural sector, karena lebih mengarah pada sektor percepatan industri, pada daerah yang memberlakukan percepatan tersebut, rusaknya lahan pertanian di Kal-Tim terlihat dari besarnya pembukaan lahan untuk kelapa sawit. Pemicu dari tingginya hasil yang didapat dan meningkatkan taraf hidup masyarakat yang mulai berpindah menjadi petani kelapa sawit (CPO).

c. Walaupun kemudian angka melek huruf mengalami peningkatan sampai $99,0 \%$ dan pengangguran terus mengalami penurunan, tetapi kualitas SDM daerah terutama pada teknologi masih kurang. Hal ini terlihat dari angka Jenjang Pendidikan dalam Kinerja Pembangunan Bidang Pendidikan Prov. Kal-Tim 2009-2010, seperti SD/MI terealisasi 30,73\% dan hampir mencapai target sebesar 34\%, untuk SLP/MTS terukur realisasi sebesar $21,95 \%$ dan hampir mencapai target sebesar 23\%. SLA/MA mencapai realisasi sebesar $28,18 \%$ dan target yang ingin dicapai sebesar $31 \%$. Terakhir untuk yang mampu mencapai tingkat lulusan Perguruan Tinggi sebesar 6\% sedangka angka target yang ingin dicapai sebesar 75\% Terlihat bahwa tingginya angka melek huruf, dengan jenjang pendidikan tidak imbang, terjadi piramida kesenjangan tingkat pendidikan untuk lulusan perguruan tinggi sangat kecil sekali. Sehingga kualitas SDM yang rendah dari tingkat jenjang pendidikan, kemudian memberikan dampak kesenjangan terhadap masalah upah buruh pada SDM asing dan SDM daerah, yang seringkali membuat munculnya konflik kekerasan seperti pada daerah pertambangan.(BPS: 9201.64)

2. Potensi ketergantungan host country, masalah informasi yang seringkali searah menyebabkan muncul pola ketergantungan host country yang menerima cost investasi asing sebesar $\mathrm{Rp}$ 63,37 Triliun dalam bargaining position, terlihat sekali para investor asing mengalami perlakuan "spesial" dari pemerintah daerah (weakness state). Padahal dalam hal posisi tawar daerah lebih kuat karena memiliki 
hak atas kepemilikan SDA daerah, tetapi karena kurangnya SDM yang potensial dan teknologi, maka pemerintah membuka pintu pembangunan ekonomi untuk para investor asing. Sehingga pasca pencairan cost investor asing, maka masuknya SDM asing dan teknologinya juga diterima seluas-luasnya oleh pemerintah daerah.

3. Potensi munculnya Bottle-neck di daerah Kal-Tim, seperti tingginya harga bahan makanan dari tingginya kemampuan demand masyarakat, akibat tingginya upah buruh, sehingga hanya sedikit masyarakat yang mampu mengikuti demand kebutuhan pada harga pasar saja. Sedangkan masih banyak masyarakat yang tidak terlibat secara langsung dalam percepatan pembangunan ini tidak mampu mengikutinya.

4. Potensi kerusakan lingkungan akibatnya terbukanya lahan untuk kelapa sawit (luas 478.853,50 ha) dengan produksi mencapai 1,69 juta ton dan tambang seperti batubara dengan hasil produksi 25 Triliun metric ton, serta munculnya 742 kasus lahan yang tumpang tindih tersebar di 14 daerah KalTim (dalam Rakergub 2011).

5. Potensi "mental" korupsi pada host country, hal ini karena lemahnya sistem administrasi pemerintah daerah, terutama masalah perijinan (penyelesaian dokumen kesepakatan) dan "mata rantai" birokrasi daerah terutama saat mereka melakukan "Check Price" dan "Quality Control", maka dengan dasar Pembentukkan Tim
Rencana Aksi Daerah Pemberantasan Korupsi (RAD-PK) sesuai Pergub Nomor 52 Tahun 2008, Pembentukan Tim Sekretarian Koordinasi, Monitoring dan Evaluasi, terus dilakukan upaya investigasi dalam pencairan dana investasi asing ke pemerintahan daerah Kal-Tim, agar dana-dana tersebut memang dioperasionalkan dalam pembangunan industri Kal-Tim. Potensi lemahnya akan Quality control pada setiap investor yang masuk ke Kal-Tim, dan ini kadang menyebabkan kualitas sektor pembangunan tidak berjalan baik, seperti kontrol terhadap kualitas pembangunan jalan, jembatan dan pabrik-pabrik industri.

6. Potensi "Over-investment" bisa terjadi di Kal-Tim, apabila pemerintah daerah terlalu membuka "pintu" bagi para investor asing, maka tingginya kedatangan investor bisa membuat seluruh "wajah" pembangunan Kal-Tim berubah pada "perilaku" pembangunan investor asing saja. Sedangkan para investor dalam negeri dan masyarakat daerah hanya mampu sebagai "penikmat" dan "penonton" saja.

\section{Alternatif kebijakan dalam minimalisir risk host country}

Hasil dari keberadan resiko-resiko diatas, kemudian diformulasikan dalam bentuk kebijakan daerah yang meminimalisir resiko jangka panjang, salah satunya adalah 'stockpiling release policy', terutama pada 
SDA yang proses pembaharuannya sulit, artinya tidak menghabiskan cadangan SDA untuk ekspor semua, walaupun seperti migas permintaanya sangat tinggi. Pemerintah harus mengupayakan pada pembangunan ekspor non migas, terlebih proses pembaharuannya mudah dan mampu menyerap lapangan pekerjaan dalam proses jangka panjang kedepan.

Strategi diatas juga didukung oleh pendekatan kerjasama antar daerah yang karena struktur hubungannya merupakan 'relasi horizontal' ke arah semangat kolaborasi dalam 'collective action', terutama antar daerah provinsi dengan pusat dalam melihat potensi keberadaan investasi asing. Terutama bersama-sama membuat aturan dasar undangundang yang mengarah pada proteksi SDA. Kerjasama dan kolaborasi ini diharapkan untuk kepentingan bersama yang mendorong dua atau lebih pemerintah daerah, untuk memecahkan masalah-masalah diatas secara bersama. Berbagai tindakan diarahkan pada jaringan simetris antar daerah, mengenai informasi mengenai investor asing sebagai mitra dalam hubungan yang kuat antar daerah dengan pusat. Sehingga setiap permasalahan yang melibatkan konflik di daerah seperti permasalahan tambang batubara, dapat cepat diselesaikan melalui mekanisme kemitraan yang kuat antar daerah dan bantuan dari pemerintahan Pusat. (Hardi Warsono : 78-91)

Jaringan kerjasama antar Pusat dengan Daerah menjadi solid, apabila proses posisi tawar menawar dengan investor asing, terutama masalah bagi hasil, dilakukan melalui mekanisme diatas, sehingga keunggulan lobilobi yang tinggi terlihat dari hasil keuntungan yang didapat dari investor asing, hal ini dikarenakan daerah yang memiliki SDA secara langsung. Tekanan pada proses eksploitasi penggalian SDA akan dilakukan kelompok bisnis lokal dengan dukungan penuh dari masyarakat, pemerintah daerah dan pemerintah pusat, dapat menambah devisa dari adanya kerjasama tersebut, sehingga dengan adanya otonomi daerah tidak melemahkan sinergi antara pemerintah pusat, pemerintah provinsi dan pemerintah daerah. Kolaborasi dan koordinasi pemerintah yang baik, akan mampu menyelesaikan konflik-konflik yang muncul pasca keberadaan investor asing, seperti konflik kesenjangan infrastruktur, kesenjangan upah buruh, kerusakan lahan akibat eksplorasi lahan, sehingga memunculkan bencana banjir dan tanah longsor, serta konflik mengenai perbatasan dan kepemilikan hak atas lahan.

Dalam menentukan visi dan misi percepatan pembangunan daerah Kal-Tim, terutama pada keberadaan investor asing di daerah Kal-Tim, memerlukan kemampuan kontrol untuk mencapai tujuan (output) dari keputusan pemerintah daerah. Diantaranya keberadaan para investor asing dibuka dengan keberadaan, UU No.1/1967 tentang Penanaman Modal Asing (PMA) dan UU No.6/1968 tentang Penanaman Modal Dalam Negeri (PMDN), yang kemudian direvisi melalui UU No.11/1970 PMA dan UU No.12/1970 PMDN. Secara nasional, dijadikan dasar dalam terbukanya pintu investasi 
pembangunan masing-masing daerah. Keberadaan UU ini sebagai bentuk perlindungan hukum bagi masuknya para investor asing. Selain adanya perlindungan bagi investor asing, terlihat juga perlindungan daerah yang otoritasnya tercantum dalam UU No.25 Tahun 2007 tentang Penanaman Modal. Hal ini harusnya memperlihatkan bahwa kontrol besar masih berada pada penerima investor asing, seperti pada pasal 10 masalah tenaga kerja, mengenai kompensasi masalah tenaga kerja terutama pada warga negara Indonesia yang harus maksimal. Kemudian dalam pasal 12 yang mencantumkan tentang pemberlakuan mengenai, adanya berbagai usaha perlidungan sebagai bentuk kontrol pemerintah daerah. Seperti pemerintah menetapkan bidang usaha yang terbuka dengan persyaratan berdasarkan kriteria kepentingan nasional, yaitu perlindungan sumber daya alam, perlindungan, pengembangan usaha mikro, kecil, menengah, dan koperasi, pengawasan produksi dan distribusi, peningkatan kapasitas teknologi, partisipasi modal dalam negeri, serta kerja sama dengan badan usaha yang ditunjuk oleh pemerintah.

Atas dasar kontrol dari berbagai ketentuan pasal yang berlaku pada masalah penanaman modal asing, maka pemerintah daerah berhak melakukan berbagai upaya dan usaha dalam percepatan pembangunan daerah, dalam rangka mewujudkan tujuan pembangunan daerah tersebut. Penerapan sanksi hukum dilakukan dalam upaya pemberlakukan kontrol, terhadap para investor asing yang 'nakal' dan menyalahi aturan yang sifatnya legal, terlebih mengganggu sektor UKM dan ekonomi nasional.

Setidaknya ini adalah langkah strategis dalam sebuah usaha 'bargaining position' pemerintah daerah, untuk menindaklanjuti kontrol terhadap keberadaan investor asing. Usaha ini juga dalam meningkatkan devisa daerah atas segala kepemilikan SDA daerah. Strategi kontrol terbaik dari pemerintah dengan dasar hukum yang legal, dapat ditingkatkan agar bentuk ketergantungan terhadap pemilik modal asing tidak terlalu tinggi.

Sinergi kolaborasi antar pemerintah dengan kelompok pembisnis lokal, dalam kebijakan 'catch-up', dengan selalu mengupayakan apa yang bisa mereka buat, sebisa mungkin kita juga mampu membuatnya. Pendekatan cluster kawasan khusus yang memiliki SDA terbaik, hendaknya dibina sebaik-baiknya, bahkan diberikan berbagai akses kemudahan, sesuai dengan cluster permintaan pasar luar negeri. Pendekatan cluster sangat mengupayakan pada SDA terbaik, yang kemudian dikelola sehingga menjadi produk unggulan, dalam setiap hubungan kerjasama yang memiliki nilai sangat sensitif atau tinggi. Pengusaha eksportir didukung oleh pemerintah mulai dari penyediaan modal, memberikan fasilitas dan informasi bisnis yang cepat bagi kelompok bisnis, menyediakan fasilitas 'testing standar' untuk produk ekspor dan juga tentunya didukung oleh 'certificate of quality' yang baik, terutama untuk barang-barang ekspor 
baik migas dan migas yang menjadi 'primadona', sehingga upaya dalam meningkatkan keberadaan kelompok bisnis lokal dan UKM sebagai salah satu kebijakan alternatif dalam percepatan pembangunan daerah Kal-Tim.

Upaya kolaborasi pemerintah dengan pihak swasta semakin solid, memberikan ruang dan kepercayaan yang cukup bagi pihak swasta domestik, terutama dalam pembinaan standarisasi sebuah produk dan sertifikasinya, sehingga setiap keputusan eksploitasi SDA tidak langsung diberikan kepada investor asing saja. Jangka pendek memang akan terlihat proses pembelajaran mengelola eksploitasi berjalan alot, seperti kurangnya pengalaman, tetapi jangka panjang adalah memberikan pembelajaran terbaik bagi pihak swasta domestik dalam mengelola eksploitasi SDA daerah sendiri dan mampu menyerah tenaga kerja daerah itu sendiri.

\section{Kesimpulan}

Adanya Masterplan Percepatan dan Perluasan Pembangunan Ekonomi Indonesia yang dicanangkan oleh pemerintah pusat, menjadikan Kal-Tim sebagai salahsatu Koridor Ekonomi Nasional dengan basis Kawasan Ekonomi Khusus, sehingga membuka pintu bagi investor asing sebagai bentuk dukungan daerah.

Keberadaan investasi asing di Kal-Tim dalam kerangka kerjasama bilateral dengan Kor-Sel dan Rusia, ternyata memberikan alternatif pilihan rasional bagi pembuat kebijakan pemerintah daerah Kal-Tim, bahwa selain mengejar cost dan benefit dari keberadaan investasi asing tersebut, ternyata mampu menciptakan rasio resiko yang dalam jangka waktu lama bisa menjadi "boomerang" tersendiri.

Hasilnya dalam pilihan paling rasional bagi pemerintah daerah adalah berusaha memaksimalkan keuntungan dengan sebesarbesarnya, dan meminimalisir resiko dengan sekecil-kecilnya untuk keberadaan investor asing bagi keseluruhan masyarakat daerah. Terlihat dari perbandingan rasio cost, benefit dan risk dalam pilihan rasional bagi pemerintah daerah Kal-Tim dalam kerjasama bilateral. 
Investasi Asing Di Kalimantan Timur Dalam Kerjasama Bilateral: Tinjauan Melalui Perspektif Rational Choice

\section{Daftar Pustaka}

Aranson, Peter H, 1996, American Government Strategy and Choice, Whinthrop Publisher, Cambridge, Massachusetts.

Badan Pusat Statistik (BPS) Provinsi Kalimantan Timur, 2010, Kalimantan Timur Dalam Angka 2010, Samarinda, Badan Pusat Statistik (BPS) Provinsi Kalimantan Timur.

Gilpin, Robert Chapter The State and the Multinationals dalam Robert Gilpin, 2001, Global Political Economy Understanding the International Economic Order, Princeton University Press, New Jersey.

Gilbert, Alan dan Josef Gugler, 1996, Urbanisasi dan Kemiskinan di Dunia Ketiga, PT. Tiara Wacana Yogya, Yogyakarta. Yogyakarta.

Hadiwinata, Bob Sugeng, 2002, Politik Bisnis Internasional, Penerbit. KANISIUS,

Kondisi Sosial Ekonomi dan Indikator Penting Kalimantan Timur, Katalog BPS : 9201.64, Edisi September 2010. Millennium Development Goals. Badan Pusat Statistik Provinsi Kalimantan Timur.

Laporan Hasil Evaluasi Kinerja Pembangunan Daerah Kal-Tim dalam Realisasi Investasi Kal-Tim dan Penyerapan Tenaga Kerja. Laporan BPID Kal-Tim, Tahun 2008, Tim Independen 
BKPD Kal-Tim 2008 Universitas Mulawarman, dalam http://www.docstoc.com/docs/3901011/ Provinsi-Kalimantan-Timur

Nurzaman, Heri 12 Mei 2010, Mekanisme Investasi Modal Asing Dalam Pertambangan Nasional", dipresentasikan dalan In-depth discussion yang diselenggarakan oleh Jatnika Legal Research \& Training Centre.pdf

Rapoport, Anatol, 1970, Two - Person Game Theory, The Essential Ideas, Ann Arbor, The University of Michican Press, Canada.

Risse, Thomas, 2000, International Organiation Communicative Action in World Politics, The IO Foundations and the Massachussets of Technology, Massachussets.

Oatley, Thomas, 2006, International Economy Interest and Institutions in the Global Economy, Pearson Education Inc, New York.

World Bank's Indonesia Poverty Team (INDOPOV), Edisi 2006, Revitalisasi Ekonomi Perdesaan : Penilaian Iklim Investasi Pedesaan yang dihadapi Perusahaan Non-Petani di Tingkat Kabupaten

Wahab, Solichin Abdul, 2008, Analisis Kebijakan, Dari Formulasi ke Implementasi Kebijakan Negara, PT. Bumi Aksara, Jakarta.

Winarno, Budi, 2002, Teori dan Proses Kebijakan Publik, Media Pressindo, Yogyakarta.

Warsono, Hardi, 2009, Networking dalam Intergovernmental Management, "Dialogue" JIAKP, Vol.6, No.1, Januari 2009. Dialog Jurnal Ilmu Administrasi dan Kebijakan Publik.

Angka Investasi Kal-Tim dalam http://bppmd.go.id

Kebijakan Umum APBD di Kal-Tim dalam http://Kal-Timprov.go.id Asing, pdf

Undang-Undang Republik Indonesia No.01 Tahun 1967, Tentang Penanaman Modal 